\title{
The Implications of International Urban Rail Transit Operation Project Management: a Case Study of Jerusalem`s Light Rail Project
}

\author{
Yi Guo \\ Shenzhen Metro International Investment \& Consulting Co., Ltd, Shenzhen, China \\ Email: szguoyi@foxmail.com
}

\begin{abstract}
Jerusalem light rail project as the first light rail line in Israel has already been opened and in operation for 5 years, with good operation condition and quite similar operation mode and characteristics to Tel Aviv light rail project. The technical leading member of its operational consortium, French Veolia, has rich experience in overseas rail transit operation and had fully participated in the Jerusalem light rail project since 2005 till being expelled from Israel in 2015 . This paper analysis Veolia's 10-year experience and lessons obtained from operation of the Jerusalem light rail project. It was reflected the actual operation environment of the project in Israel and can be used as a crucial reference for the operation of international rail transit.
\end{abstract}

Keywords: international project, urban rail transit operation, project management, Jerusalem light rail

\section{Cooperation model of the Jerusalem light rail}

In 1995, the government of Jerusalem began to plan and prepare for the construction of light rail. In 2011, the light rail was officially opened for operation, with $13 \mathrm{~km}$ in length, 23 ground stations, and 1 vehicle depot. This light rail is equipped with 46 five-module tramcars of type CITADIS 302 provided by French Alston ( 2 tramcars are coupled in one running group and totally 23 groups are formed).

The light rail adopts a 30-year BOT construction method. Its operation consortium is formed by Harel (a local investment company of Israel, taking a share of 20\%), Polar Light Investment Company (taking a share of 17.5\%), Israeli Infrastructure Fund (a state-owned investment company, similar to urban construction investment company in China, taking a share of 10\%), Ashtrom Group (construction contractor, taking a share of 27.5\%), French Alston (vehicle contractor, taking a share of 20\%), and Veolia Transport (operation contractor, taking a share of 5\%).

In 2015, under pressure from various parties, Veolia promised to secede from the operational consortium by giving up its share (5\%) and signed an agreement with DAN, the second largest bus company in Israel, to sell its share to DAN. However, restricted by the influence of the political consortium, Veolia stopped the negotiation with DAN, instead turned to negotiate with EGGED, and promised to provide EGGED with long-term operational consulting services till EGGED possessing the independent operation ability. Later, Veolia was taken to court by DAN for breach of contract. Due to the tight seceding time, Veolia had to resell its entire share (5\%) to Israeli state-owned infrastructure investment company under the pressure of the government.

\section{Veolia's experience in the operation of Jerusalem light rail project}

\subsection{Cooperating with local private and state-owned enterprises and focusing on operational tech- nology consulting \\ Veolia only took a share of 5\% in the BOT consortium and was only responsible for the preparation and management of operational technology. Other additional public affairs were handled by the local private and state-owned enterprise partners to avoid a series of problems caused by foreign company for being unfamiliar with the local circumstances.}

\subsection{Outputting high-end technology investment instead of low-end labor force}

As this project was a BOT project, Veolia had invested in the project, but the investment was relatively smaller than other shareholders. Veolia mainly provided technology consulting service and served as operational expert to guide the operational preparation work of the consortium. Instead of dispatching a large scale of operation team under integrated system or low-end operation personnel, Veolia only dispatched a small scale of middle and high-level technical management personnel to provide high-end technology consulting management service, make strategy, formulate institution and standard 
and control the flow so as to reduce human cost and employment risk, improve the management efficiency, and realize the transformation from doing it by self to guiding local people to do and the transformation from administrative control to shareholding control.

\subsection{Global selection and recruitment of operational talents to create a diversified international professional operation team}

Veolia's operation team in Jerusalem was a diversified international professional operation team with members not only limited to Israelis or French (also including Germans, Australians, Austrians, and British) recruited at international level. The core members came from the branches of TRANSDEV all over the world. The remained members were professional managers and experts specially recruited for marketing of the Jerusalem project if only they passed the operation manager test and other qualification accreditation regulated by railway laws of Israel.

\subsection{Providing a complete training service to cultivate a high-quality local team}

In order to provide local employees with training well, Veolia had started the training plan for local employees in 2005. The first batch of recruited employees was sent to the training bases of TRANSDEV and Alston to receive theoretical and practical training. To this end, Veolia had set up a training system for the light rail company. Due to continuous delay of the opening date, sufficient time was left for the training. The subsequent training for new employees was mainly provided by teachers from Veolia, with the assistance of the first batch of employees studying in France. In this way, a lot of labor cost was saved.

Israel ranks top three in the world in terms of education. $22 \%$ of its citizens have received higher education and $90 \%$ of its citizens have graduated from senior high school. Besides, Israel has railway lines of more than $1000 \mathrm{~km}$, more than 30 years of experience in railway operation, and has certain railway educational foundation. The training work and the establishment of the training system should be started early. Backbone employees should be trained firstly. The subsequent training can gradually be provided by local people to reduce the requirement for teachers in quantity and time and reduce the training cost.

\subsection{Taking into full consideration the European management standard and the local conditions in Israel}

Relying on Veolia's parent company's extensive experience and know-how in public transit operation management, an optimal technical operation and management solution was formulated as per the specific conditions in Israel to provide passengers with excellent and efficient travel service. The operation of this light rail in Israel was mainly conducted in accordance with European standards and the training and examination taken by the operation managers were also based on German light rail system. Therefore, the Tel Aviv project cannot fully abide by European standards. But it is also needed to understand the local special conditions requirement of Israel and formulate suitable operation scheme.

\subsection{Working closely with security companies and local police to ensure the operational safety}

In early stage of the light rail operation, each station and each compartment had already been arranged with special security personnel to assist in maintaining the order and safety inside and outside the vehicle. However, at a night in October 2014, a group of Islam extremists deliberately drove car to dash against the light rail station. As a result, among the people waiting at the station and the nearby passersby, one person died, and many persons got injured. This was the only accident happened in the 5 years since the opening of the light rail. There was no direct terrorist attack event both on the train and at stations. As Israel is an area with high incidence of terrorist attacks, the operator needs to work closely with security contractor and local police to respond quickly to avoid the happening of such event.

\section{The implications of Veolia's operation in Jerusalem}

\subsection{Insufficient prediction of delay in the project duration}

The light rail project started construction in 2002 and was planned to open in 2006. However, due to the disputes over safety measures, drivers' remunerations, engineering construction, contract changes and so on, the project encountered frequent resistance, so that the progress was slowed down again and again, and the opening ceremony was postponed four times. Eventually, the rail connection was completed in 2010 and the project was completed at the beginning of 2011. Further, the opening time was put off to December 2011 due to the disputes from all parties over the selection of independent engineer responsible for acceptance of crossroad signal lights. The opening for operation of the Jerusalem light rail project was postponed for 5 years, and the opening date was changed 4 times, which brought a large amount of additional costs to the 
operator and disturbed the normal operational preparation process. But in the construction of rail transit in western countries, long-term engineering delay is quite common.

\subsection{Insufficient capability to manage and control each subsystem contractor}

As for the Jerusalem light rail project, the system equipment maintenance and care were also distributed to each subsystem contractor. But there were frequent problems in integration. For instance, after the opening of the line, failures that may affect the normal operation frequently occurred on the $\mathrm{A} / \mathrm{C}$, electrical and communication devices of the train, resulting in operational interruption. For many times, the image of train even disappeared on the screen of OCC and got fully out of control.

The problem of AFC system was even more serious. The system of the entire line collapsed on the first day of official opening after no-load trial operation. Over a dispute between the operator and government officials, they had to announce two weeks of free operation to give the system supplier enough time to restore the system. The trains were degraded for operation at a running interval of $21 \mathrm{~min}$ and only 14 sets of trains were on the line, causing serious dissatisfaction of citizens.

Additionally, a large amount of works in maintenance and care of subsystems for operation of the Tel Aviv light rail were also subcontracted, and the equipment and maintenance and care teams adopted were from different countries. Compared with the unified equipment supplier of Ethiopian project, it is considerably difficult to manage and integrate the equipment suppliers with different standards from different countries and clearly divide the responsibilities of equipment suppliers in the tendering documents. This would bring large risk to the normal operational evaluation. In the Jerusalem project, it was still difficult to ensure a stable operation even all the equipment adopted unified standards of France. Hence, for the Tel Aviv project, special attention should be paid to management of the equipment suppliers from multiple countries.

\subsection{Insufficient ability to coordinate with external interfaces of the operation}

From the beginning of the project, there have already been many disputes between the BOT consortium and the owner.

The first dispute is about the relationship with the owner. This project is not a BOT project in full sense. Considering the recycling cost after 30 years, the government clearly stated in the contract that any additional investment beyond the contract (ranging from spare parts to additional trains) must be approved by the government. In this contract, Veolia did not get a valid authorization. Meanwhile, the less efficient approval of the government results in low level of service and slow procurement. For example, in the winter of 2013, Jerusalem was forecasted to have a rare blizzard. In response to this weather, Veolia asked for purchasing heaters to melt snow. However due to the slow approval of the government, the turnout was buried eventually during the blizzard, leading to shutdown of the entire line. Nevertheless, the owner attributed the liability to Veolia's insufficient preparation.

The second dispute is about the licensing for operation (PTO) and the evaluation of conditions for safety and trial operation. In the first evaluation, the government had no relevant experience. The formulation of the light rail management regulations was delayed, and multi-national evaluation standards were adopted, causing great dissatisfaction of Veolia and the long-term unavailability of the evaluation. The dispute was started from 2009 and even applied for arbitration. In detail, Veolia claimed compensation from the owner for the loss caused by the delay in evaluation, while the owner insisted on making no compensation. This directly led to the fourth put-off of the opening date.

The third dispute is about the consideration of integrating the light rail operation system with other ground transit systems. Before the opening of the line, Veolia did not realize that it was needed to get the government's approval for giving priority to train signal at level crossing. Until the trial operation in 2010, it was found that the operation time of the whole journey was not the designed $42 \mathrm{~min}$ but as long as $80 \mathrm{~min}$ and the light rail system was incompatible with the traffic light system. This extra cost in the reconstruction again triggered a dispute between Veolia and the owner till arbitration. Veolia requested for putting off the opening time and letting the owner undertake the loss caused by the put-off and the expense in equipment reconstruction. However, the technical integration with the signal system of level crossing still had not been completed even after the opening for operation of the project.

\subsection{Under-estimated passenger flow, poor service quality and low passenger satisfaction}

In 2013 and 2014, the owner successively invited a third party to conduct passenger satisfaction survey on the operation of the light rail. The survey result was astonishing. For instance, the satisfaction in 2013 was only scored 66 points (full score: 100 points) and that in 2014 was merely scored 74 points (full score: 100 points); the score of the congestion in peak hours was only 45 points, that of ticketing convenience was 59 points and that of ticketing inspection satisfaction was 60 points.

After the opening of the light rail, there was no station agent to provide passenger with guidance at station. Many passengers did not know how to buy a ticket. Meanwhile, only one TVM was provided on one side of the platform. In this 
circumstance, long queues of passengers were formed to buy tickets and many people even evaded fares.

The ticketing inspection system of the light rail was recognized by passengers. Namely, if they were found taking the train without ticket, they would be punished with a fine of NIS 186 and not allowed to take the train on the next day even with ticket and the tick would not be refunded. The passengers were seriously dissatisfied with this policy and had filled a lawsuit to the court for many times. The court also required the owner to modify this policy. According to statistics, the income from this penalty reached up to NIS 2.4 million in 2014.

After the opening of the Jerusalem light rail, the actual passenger flow far exceeded the expectation, where the passengers not only included Jews and tourists but also included Arabs. It was the underestimated passenger flow in design stage that caused the poor service quality and low satisfaction level. The KPI evaluation criteria of Tel Aviv owner have very high requirements for customer relationships, passenger information, and customer service calls and the ticketing inspection rate is required to reach $12 \%$. In contrast, the actual operation of Jerusalem light rail is very unsatisfactory and also reflects the difficulty in its operation in the future.

\subsection{Insufficient consideration of labor employment risk}

During the operation of the Jerusalem project, salary and working environment had become the cause of striking of drivers and security personnel many times. The labor cost in Israel is high, especially that of drivers. It is necessary to consider the labor employment risk and the care for employees; otherwise, drivers may strike, further affecting the normal operation evaluation.

\section{Conclusion}

Veolia is the first foreign operator trying to operate rail transit in such a politically sensitive area as Israel. Although the 30-year operation contract was not successfully completed, a lot of useful experience and lessons were obtained from the 10 years of operation, especially in the 5 years after the opening of the line. This experience and lessons can provide first-hand operational performance information and make clearer the light rail operation environment in Israel, to facilitate making corresponding preparations in advance, giving more accurate risk prediction and control measures in the operation scheme and gaining relevant contract in Israel.

\section{$\underline{\text { References }}$}

[1] Nolte, A., \& Yacobi, H. Politics, infrastructure, and representation: the case of Jerusalem's light rail. Cities. 2015; 43(3): 28-36.

[2] Amina Nolte. Political infrastructure and the politics of infrastructure: the Jerusalem light rail. City, Taylor \& Francis Journals. 2016; 20(3): 441-454.

[3] Petersburg, O. Jerusalem light rail - a microcosm of a city divided - the children's intifada. Israel Faxx. 2014.

[4] JOSH LEPMAN. Jerusalem light rail moves forward despite protest. Trains. 2010; 70(6): 21.

[5] Sandler Neal. Booming ridership prompts push for more light rail in Jerusalem. ENR: Engineering News-Record. 2013; 281(17): 1.

[6] Association, A. R. Capital metro: Canberra's light rail project in a global context. Light Rail Transit. 2015.

[7] Mochizuki, A., Nakagawa, D., \& Kasahara, T.. Meanings of Toyama light rail project on Japanese public transport policy. Journal of the City Planning Institute of Japan. 2007; 42.

[8] Zhao, Q. Solution of closed circuit television monitoring system for Changchun light rail project in the third phase. Railway Signalling \& Communication Engineering. 2013.

[9] Zhang, W. Analysis on the causes of the loss of the light rail project in Saudi Arabia of China railway construction and implications. Shanxi Science and Technology. 2012.

[10] Finnigan, L. The Portland Milwaukie light rail project connecting a metropolitan area, one segment at a time. Right of Way. 2013. 